\title{
Design, synthesis, antifungal activity, and QM/MM docking study of two azole derivatives with indole ring
}

\author{
Suat SARI ${ }^{1}$ * (D), Didem KART ${ }^{2}$ (D) \\ 1 Department of Pharmaceutical Chemistry, Faculty of Pharmacy, Hacettepe University, Sihhiye 06100 Ankara, \\ Turkey. \\ 2 Department of Pharmaceutical Microbiology, Faculty of Pharmacy, Hacettepe University, Sihhiye 06100 Ankara, \\ Turkey. \\ * Corresponding Author. E-mail: suat.sari@hacettepe.edu.tr (S.S.); Tel. +90-312-305 1872.
}

Received: 06 May 2020 / Revised: 17 June 2020/ Accepted: 11 July 2020

\begin{abstract}
Systemic candidiasis is a major health issue for immunocompromised individuals due to the increase in drug-resistance among Candida spp., which are prevalent pathogenic fungi responsible for many types of fungal infections. Azoles are among the most preferred antifungal class for systemic candidiasis with broad antifungal spectrum and systemic availability. In this study, we synthesized and tested antifungal effects of two new indole derivatives to investigate the impact of indole on the activity of azole antifungal compounds and to find potent derivatives against Candida spp. including resistant strains and biofilms. 1-(4-Chlorophenyl)-2-(1H-imidazol-1yl)ethanol $1 \mathrm{H}$-indole-2-carboxylate (4a) showed excellent antifungal profile with several times more potent activity against the tested species including a fluconazole-resistant $C$. tropicalis isolate. The minimum inhibitory concentration (MIC) of $4 \mathbf{a}$ was $0.03125 \mu \mathrm{g} / \mathrm{ml}$ against C. albicans, which was $0.5 \mu \mathrm{g} / \mathrm{ml}$ for fluconazole. The compound also showed promising biofilm inhibitory effect compared to amphotericin B. The importance of indole was demonstrated through molecular docking studies with the structure of C. albicans CYP51, the established target of azole antifungals, using different protocols. QM/MM docking approach yielded excellent results and accuracy, especially regarding metal interactions. As a result, indole could be a very useful fragment to design new and highly potent antifungal compounds in azole structure.
\end{abstract}

KEYWORDS: Azole; antifungal; biofilm; Candida albicans; CYP51; indole; induced fit docking; QM/MM docking.

\section{INTRODUCTION}

Systemic candidiasis is a major health issue for immunocompromised individuals due to increasing drug-resistance among Candida spp., which are prevalent pathogenic fungi responsible for many types of fungal infections. Although $C$. albicans is the most commonly identified species in candidiasis, the rise of infections caused by non-albicans species with natural and acquired drug resistance is of great concern [1]. Azoles are among the most preferred antifungal class owing to a number of advantages, such as efficacy spectrum and systemic availability, however their common usage comes with the issue of resistance [2]. One of the causes of drug resistance is the ability of pathogens to form biofilms, a form of pathogen colonies found on biotic and non-biotic surfaces featuring structural matrices and extracellular polymers. Most antifungal compounds are effective against biofilms only at higher doses compared to their efficacy against the planktonic forms and there is little known about the antibiofilm properties of azoles [3].

Azoles emerged as a group of antifungal drugs with the introduction of imidazole derivatives such as clotrimazole, miconazole, and oxiconazole. Ketoconazole was the first broad spectrum antifungal with oral availability (Figure 1). Triazole antifungals led to reduced toxicity and side effects with fluconazole, golden standard of azole antifungals, and to improved efficacy with itraconazole. With the second-generation triazole antifungals, such as voriconazole and isavuconazole, and tetrazole antifungals such as VT-1161 (oteseconazole), wider spectrum was obtained including several resistant species [4,5]. Azoles possess three major pharmacophores: an azole ring (imidazole, 1,2,4-triazole, or tetrazole), an aromatic ring (usually halogenated benzene), and a tail group (mainly includes aromatic, heteroaromatic, or heterocyclic moieties) attached to the alkylene linker between the azole and aromatic ring. Azoles inhibit fungal lanosterol 14ademethylase (CYP51), a cytochrome P450 enzyme that catalyzes biosynthesis of ergosterol, a crucial

How to cite this article: Sari S, Kart D. Design, synthesis, antifungal activity, and QM/MM docking study of two azole derivatives with indole ring. J Res Pharm. 2020; 24(5): 681-692. 
component of fungal cell membranes. The azole ring is the pharmacophore responsible for blocking the heme co-factor, which catalyzes the oxidation process, while the aryl and the tail groups occupy the active site and provide a tight binding [6,7]. To date, various crystallographic studies have been reported elucidating CYP51 inhibition by azoles at molecular level [8-11].
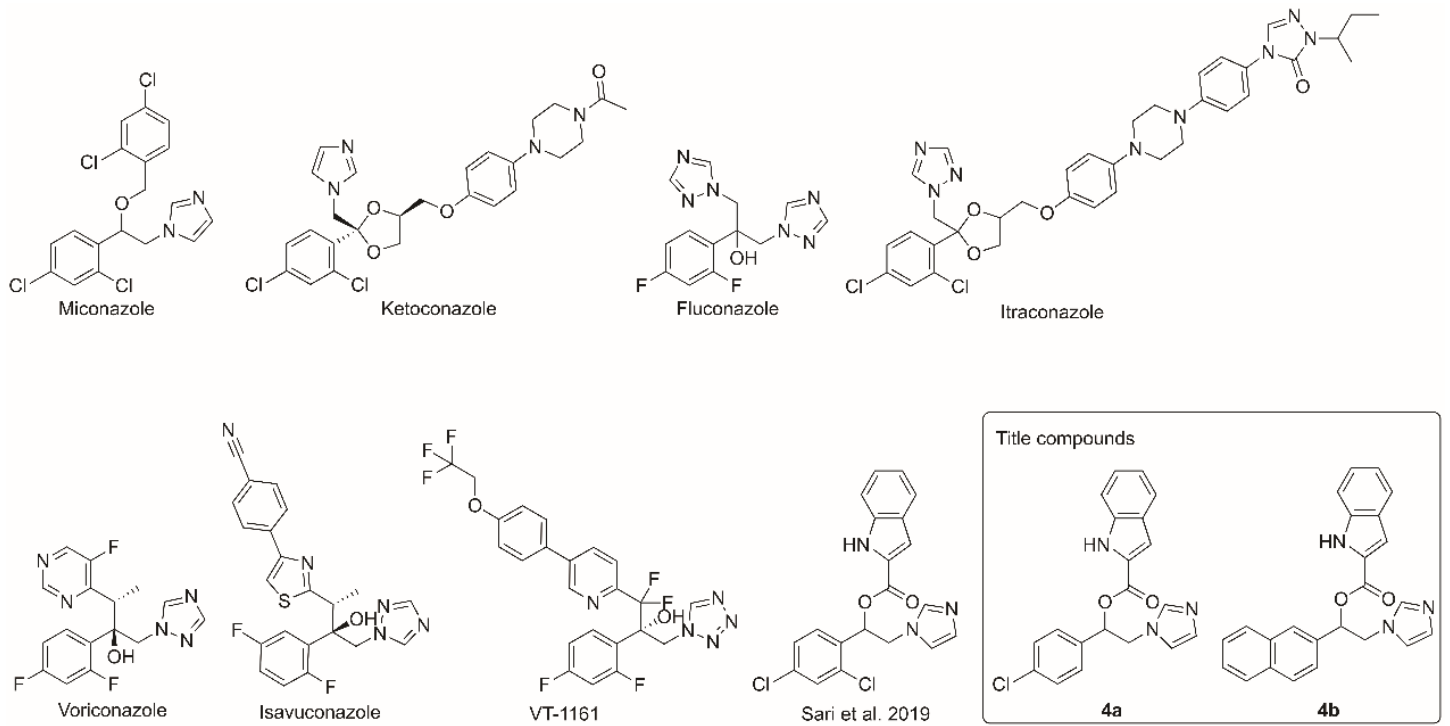

Figure 1. Azole antifungals and the title compounds.

Previously we reported a number of compounds in azole structure with antifungal effects [12,13], which include an indole derivative showing highly potent antifungal activity with a minimum inhibitory concentration (MIC) of $0.125 \mu \mathrm{g} / \mathrm{ml}$ against C. albicans (Figure 1) [14]. Thus, we designed and synthesized two novel indole derivatives, 1-(4-chlorophenyl)-2-(1H-imidazol-1-yl)ethanol $1 H$-indole-2-carboxylate (4a) and 2(1H-imidazol-1-yl)-1-(2-naphthyl)ethanol $1 H$-indole-2-carboxylate (4b) (Figure 1). The title compounds, which share the typical azole antifungal scaffold, possess imidazole as azole ring, 4-chlorophenyl or 2-naphthyl as aryl group, and indole as tail group. The title compounds were tested for their effects against susceptible and resistant Candida spp., as well as C. albicans biofilms to obtain new potent antifungal molecules. We provided a detailed in silico analysis of $C$. albicans CYP51 (CACYP51) binding of these compounds using both classical and sophisticated docking approaches such as induced fit docking, which renders limited receptor flexibility to partially represent the dynamic nature of protein-ligand complexes, and quantum mechanics/molecular mechanics $(\mathrm{QM} / \mathrm{MM})$ docking, which enables more accurate electrostatic charge assignment in the case of charge polarization, especially for metal interactions, to better model ligand-metalloenzyme complexes.

\section{RESULTS and DISCUSSION}

\subsection{Synthesis of the compounds}

Compound $\mathbf{4 a}$ and $\mathbf{4 b}$ were prepared according to the scheme in Figure 2. Briefly, 1-(4-chlorophenyl)2-(1H-imidazol-1-yl)ethanone (2a) and 2-(1H-imidazol-1-yl)-1-(2-naphthyl)ethanone (2b) were obtained by $N$ alkylation of imidazole with 2,4'-dichloroacetophenone (1a) and 2-bromo-1-(2-naphthyl)ethanone (1) with an excess of imidazole in ice bath. 1a was purchased and $\mathbf{1 b}$ was synthesized via bromination of 1-(2naphthyl)ethanone at the $2^{\text {nd }}$ position in cold acetic acid. By reduction of $\mathbf{2 a}$ and $\mathbf{2} \mathbf{b}$ with sodium borohydride $\left(\mathrm{NaBH}_{4}\right)$, their alcohol derivatives, 1-(4-chlorophenyl)-2-(1H-imidazol-1-yl)ethanol (3a) and 2-(1H-imidazol-1yl)-1-(2-naphthyl)ethanol (3b), were yielded. These starting materials and their syntheses were previously reported [15-17]. The title compounds were afforded via Steglich esterification of $\mathbf{3 a}$ and $\mathbf{3 b}$ with indole-2carboxylic acid in dichloromethane (DCM) in the presence of a coupling agent and a transacylation catalyst, $N, N$-dicyclohexylcarbodiimide (DCC) and 4-dimethylaminopyridine (DMAP), respectively [18]. 4b was converted to its $\mathrm{HCl}$ salt to improve solubility, however $\mathbf{4 a}$ was not stable as its salt. 


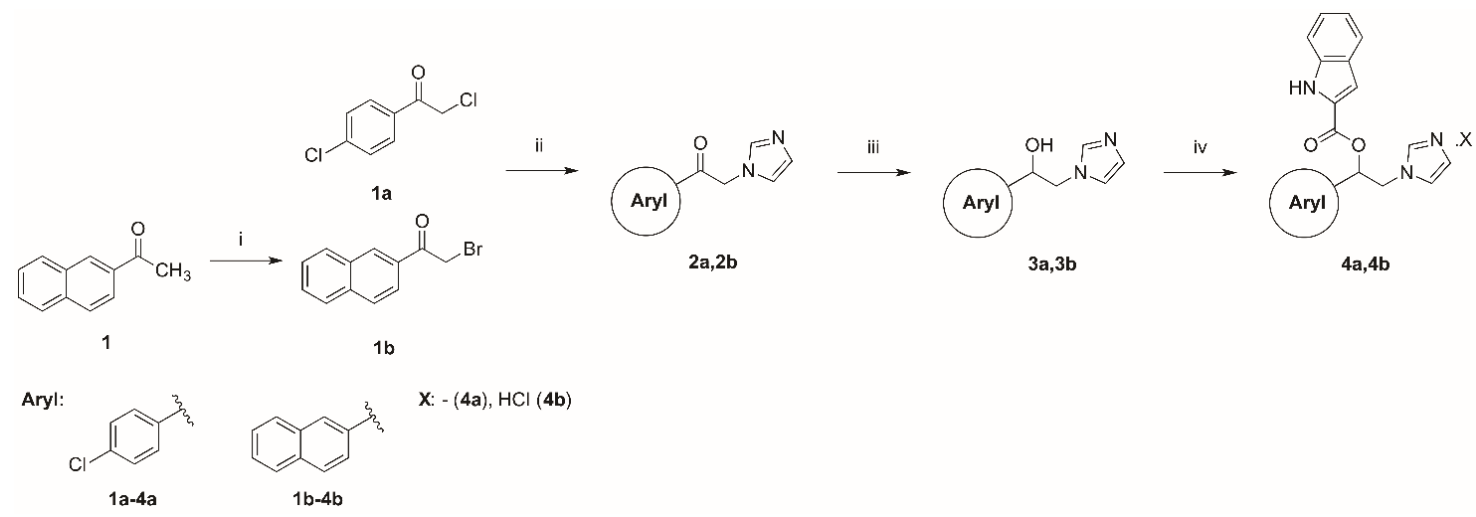

Figure 2. Synthetic scheme for the title compounds. Reagents and conditions: (i) $\mathrm{HBrO}_{3}, \mathrm{Br}_{2}, \mathrm{CH}_{3} \mathrm{COOH}, 0$ $5{ }^{\circ} \mathrm{C}$ to rt, overnight; (ii) imidazole, DMF, $0-5^{\circ} \mathrm{C}$ to rt, overnight; (iii) $\mathrm{NaBH} 4, \mathrm{CH}_{3} \mathrm{OH}, 0-5{ }^{\circ} \mathrm{C}, 1 \mathrm{~h}$; (iv) indole2-carboxylic acid, DCC, DMAP, DCM, $0-5{ }^{\circ} \mathrm{C}$ to $\mathrm{rt}, 6 \mathrm{~h}$, aethereal $\mathrm{gHCl}$ (for $4 \mathbf{b}$ ).

The reaction was initiated at $0-5^{\circ} \mathrm{C}$ to minimize formation of $N, N^{\prime}$-dicyclohexylurea (DCU), an infamous side product of DCC-coupled esterification, which precipitates during the reaction. The reaction starts with cleavage of a hydrogen from the carboxylic acid by DMAP (Figure 3). The resulting carboxylate undergoes a nucleophilic addition to DCC giving the $O$-acyl intermediate. DMAP makes a nucleophilic attack to the intermediate to trigger an addition-elimination process, which leads to hydrolysis of the $O$-acyl derivative and formation of the DCU and 1-acyl-DMAP salt. The alcoholic oxygen attacks to the carbonyl carbon of the salt, which leads to an addition-elimination process to finally yield the title esters, DCU, and DMAP unchanged [18].

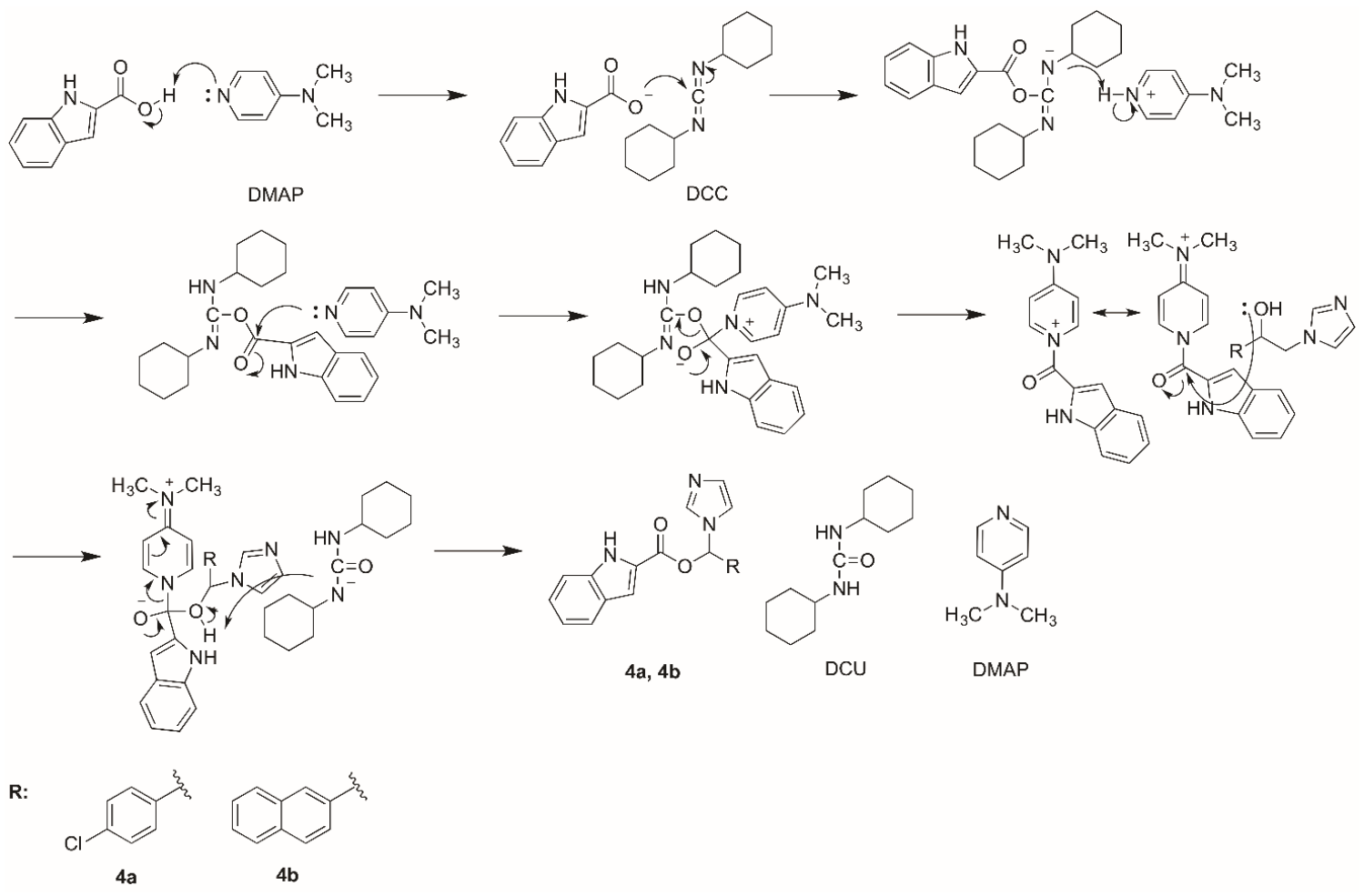

Figure 3. Esterification mechanism for the title compounds suggested according to Steglich esterification.

The title compounds were afforded as racemates at moderate yields due to DCU removal processes, which was successfully performed according to the spectral data. In the ${ }^{1} \mathrm{H}$ NMR spectra of the title compounds, the integrations were in accordance with the number of the hydrogen atoms. The chemical shifts and coupling patterns were also confirmative of their structures. The diastereotopic $\mathrm{CH}_{2}$ protons were observed at $\sim 4.5$ and $\sim 5 \mathrm{ppm}$ as doublet and multiplet for $\mathbf{4 a}$ and $\mathbf{4} \mathbf{b}$, respectively. The same trend was observed for the chiral $\mathrm{CHO}$ hydrogen, which produced a triplet signal for $4 \mathbf{a}$ but a multiplet for $\mathbf{4 b}$. This was 
probably due to the differing effect of $\mathrm{HCl}$ salt on the magnetic environments of the enantiomers of $\mathbf{4 b}$. The deshielding effect of the $\mathrm{HCl}$ salt on $\mathbf{4 b}$ protons was apparent, too, and this effect was marked the most for the imidazole $\mathrm{H}^{2}$, as expected (see Supporting Information for details). The ${ }^{13} \mathrm{C}$ NMR spectra of the compounds were in accordance with their respective ${ }^{1} \mathrm{H}$ NMR spectrum and their structures. In the LC-MS chromatograms of the compounds, one single and pure signal was observed for each compound, which gave molecular ion peaks in the respective ESI+ spectra (see Supporting Information for details).

\subsection{Antifungal activity of the compounds}

Initially, antifungal activities of the title compounds were evaluated by determining their MIC values against three American Type Culture Collection (ATCC) strains of Candida species (C. albicans, C. krusei, and C. parapsilosis) and one fluconazole-resistant $C$. tropicalis isolate. The results were impressive, especially regarding $4 \mathbf{a}$, which was found more than 10 times as potent as fluconazole against $C$. albicans (Table 1 ). The compound also showed excellent activity against $C$. krusei and C. parapsilosis, the former being intrinsically resistant to fluconazole. In addition, $\mathbf{4 a}$ was highly potent against the C. tropicalis isolate. The MIC values of fluconazole against C. krusei and C. tropicalis was found more than 100-fold higher than those of 4a. Although much less potent than $\mathbf{4 a}, \mathbf{4 b}$ showed promising antifungal potential with MIC values comparable to those of fluconazole.

Table 1. Antifungal activity results of $\mathbf{4 a}$ and $\mathbf{4 b}$.

\begin{tabular}{|c|c|c|c|c|c|c|}
\hline \multirow[b]{2}{*}{ Compound } & \multicolumn{4}{|c|}{$\operatorname{MIC}(\mu \mathrm{g} / \mathrm{ml})$} & \multicolumn{2}{|c|}{$\begin{array}{l}\text { C. albicans } \\
\text { antibiofilm }\end{array}$} \\
\hline & $\begin{array}{l}\text { C. albicans } \\
\text { ATCC } 90028\end{array}$ & $\begin{array}{c}\text { C. krusei } \\
\text { ATCC } 6258\end{array}$ & $\begin{array}{c}\text { C. } \\
\text { parapsilosis } \\
\text { ATCC } 90018\end{array}$ & $\begin{array}{c}\text { C. tropicalis } \\
\text { (resistant isolate) }\end{array}$ & $\begin{array}{l}\text { MBIC } \\
(\mu \mathrm{g} / \mathrm{ml})\end{array}$ & $\begin{array}{l}\text { MBEC } \\
(\mu \mathrm{g} / \mathrm{ml})\end{array}$ \\
\hline $4 a$ & 0.03125 & 0.25 & 0.25 & 0.5 & 8 & 512 \\
\hline $4 b$ & 4 & 64 & 4 & 128 & 64 & 124 \\
\hline Fluconazole & 0.5 & 32 & 0.5 & 64 & - & - \\
\hline Amphotericin B & - & - & - & - & 4 & 256 \\
\hline
\end{tabular}

Pathogenicity of Candida spp. also results from their ability to form biofilms. Factors such as extracellular polymeric substances and dimorphism render biofilms less vulnerable to host immune system and antifungal drugs. Therefore, antifungals show higher MIC values against the biofilms of Candida spp. than their planktonic forms [19]. $\mathbf{4 a}$ and $\mathbf{4 b}$ were tested for their ability to inhibit and eradicate C. albicans biofilms by determining minimum biofilm inhibitory and eradication concentrations (MBIC and MBEC, respectively). 4a appeared as an effective biofilm inhibitor (MBIC $=8 \mu \mathrm{g} / \mathrm{ml}$ ) with a potency close to amphotericin B (Table 1), which is known for its antibiofilm activity [20]. When the MIC values of the compounds are compared to their MBIC values, the decreased sensitivity of $C$. albicans biofilms is apparent. Like amphotericin $B$, however, the tested compounds showed limited biofilm eradication activity, which is also a typical shortcoming of azole antifungals [21].

These results clearly show that 4-chlorophenyl moiety is much better than 2-naphthyl as the aryl pharmacophore for antifungal activity of imidazole derivatives with an indole tail.

\subsection{Molecular modelling studies}

\subsubsection{Molecular descriptor calculations}

Poor pharmacokinetics and toxicity cause high attrition rates in late drug discovery stages. Eliminating such compounds in early drug development studies is crucial and in silico methods are widely used for this purpose [22]. A number of descriptors commonly used to identify drug-like chemical space (molecular weight (MW), number of rotatable bonds (RB), hydrogen bond donor and acceptor counts (HD and HA), LogP, and polar surface area (PSA)) $[23,24]$ were calculated for $\mathbf{4 a}$ and $\mathbf{4 b}$. These descriptors were found within the values ranges identified by QikProp (2019-4, Schrödinger, LLC, New York, NY, 2019) for drug-like chemical space (Table 2). The reliability of this software for the calculated descriptors was previously established [25]. According to QikProp, the compounds were also free of nonspecific reactive fragments, which are generally checked for identifying pan-assay interference compounds (PAINS). These unwanted fragments are infamous for producing to false positive results [26]. 


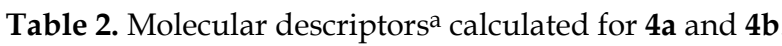

\begin{tabular}{cccccccc}
\hline Compound & $\begin{array}{c}\text { MW } \\
(\mathbf{1 3 0 - 7 2 5} \text { Da) }\end{array}$ & $\begin{array}{c}\text { RB } \\
\mathbf{( 0 - 1 5 )}\end{array}$ & $\begin{array}{c}\text { HD } \\
\mathbf{( 0 - 6 )}\end{array}$ & $\begin{array}{c}\text { HA } \\
\mathbf{( 2 - 2 0 )}\end{array}$ & $\begin{array}{c}\text { LogP } \\
\mathbf{( - 2 - 6 . 5 )}\end{array}$ & $\begin{array}{c}\text { PSA } \\
\left(\mathbf{7 - 2 0 0} \mathbf{A}^{2}\right)\end{array}$ & $\begin{array}{c}\text { Reactive } \\
\text { fragments }\end{array}$ \\
\hline $\mathbf{4 a}$ & 365.8 & 5 & 1 & 4 & 5.0 & 63.3 & 0 \\
$\mathbf{4 b}$ & 381.4 & 5 & 1 & 4 & 5.6 & 62.5 & 0 \\
\hline
\end{tabular}

a Value range defined for drug-likeness for each descriptor is provided. Number of reactive fragments should be 0 for compounds not to be defined as PAINS.

\subsubsection{Molecular docking of the compounds to CACYP51}

The crystal structure of CACYP51 used in this study (PDB ID: 5TZ1 [8]) includes VT-1161, which represents a typical binding for azole CYP51 inhibitors regarding the orientation of the tetrazole with respect to the heme co-factor, positioning of the 2,4-difluorophenl group at the bottom of the cavity, and occupation of the active site gorge by its tail (Figure 4A). The key metal coordination between tetrazole $\mathrm{N}^{4}$ and heme iron, which also coordinates with the nitrogen atoms of protoporphyrin pyrroles and one cysteine (Cys470) sidechain $\mathrm{S}^{-1}$, is also apparent in this crystal structure (Figure 4B). The aryl pharmacophore also engages in strong electrostatic interactions with the heme. The tail group interacts with Tyr118 and His377, which are among the conserved residues of eukaryotic CYP51 catalytic sites and known to engage with several other CYP51 inhibitors [8,27]. More importantly, Tyr132 makes a water-mediated H bond with the hydroxyl attached to the ethylene linker of VT-1161, which can be regarded as the fourth pharmacophore since it is conserved among the second-generation triazole and tetrazole antifungals. Actually, $\mathrm{H}$ bond interaction with this residue is considered an important molecular determinant for potent inhibition of the enzyme $[28,11]$. Coordination of azole nitrogen with the heme iron has two key aspects: the distance between the two atoms and the angle between the azole and protoporphyrin planes [29]. The nitrogen-iron distance for coordination is typically lower than $2.5 \AA$ [30]. In the case of 5TZ1, this distance is $2.15 \AA$ (Figure 4C); for other azoleCACYP51 complexes, it is measured as $2.08 \AA$ (PDB ID: 5FSA [8]) and $2.19 \AA$ (PDB ID: 5V5Z [31]). In order to keep these atoms within coordination distance and provide an effective electrostatic engagement, the azole and protoporphyrin planes should be close to perpendicular orientation [29]. In the case of 5TZ1, the angle between the two rings is $84.0^{\circ}$ (Figure $4 \mathrm{C}$ ); for 5FSA and 5V5Z, it is measured as $79.0^{\circ}$ and $79.7^{\circ}$, respectively.

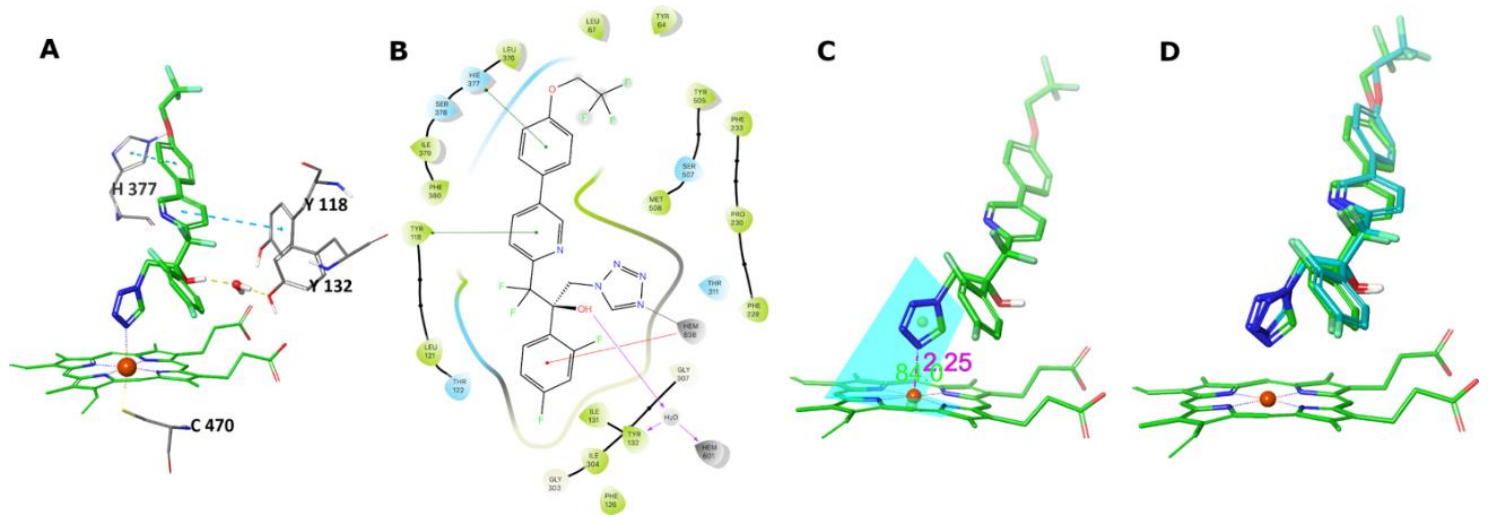

Figure 4. Co-crystallized binding mode of VT-1161 in 5TZ1 active site (A). Binding interactions of VT-1161 with 5TZ1 active site residues (B). Coordination distance between VT-1161 tetrazole $\mathrm{N}^{4}$ and heme iron (magenta) and plane angle between the tetrazole and protoporphyrin rings (green) (C). Alignment of cocrystallized VT-1161 and its binding mode predicted by Glide QPLD protocol (RMSD = $0.51 \AA$ ).

We performed molecular docking studies using four different protocols of Glide (2019-4, Schrödinger, LLC, New York, NY, 2019) [32-34]: standard precision (SP), extra precision (XP), Induced Fit (2019-4, Schrödinger, LLC, New York, NY, 20190) [35], and QM-Polarized Ligand Docking (QPLD) (2019-4, Schrödinger, LLC, New York, NY, 2019) [36], the QM/MM docking protocol of Glide. The first three protocols use conventional MM calculations. SP and XP are typical rigid-receptor docking modes with XP providing high exhaustiveness. Induced fit provides limited receptor flexibility thus better accuracy, since 
macromolecule crystal structures usually have energy constrains and ligand-receptor complexes are dynamic hand-glove models rather than rigid key-lock models. Induced fit docking is better at simulating the former at a reasonable computation burden and time cost. In these MM methods, atoms are assigned constant charges, however non-bonded interactions trigger charge polarization. In this respect, QM methods suggest more accurate charge calculations. QPLD offers ab initio method for calculating ligand atom charges polarized by the protein environment. This is especially helpful for metal interactions where charge polarization plays greater role and $\mathrm{MM}$ calculations usually fail to model them with high precision [36]. Before running molecular docking simulations of $\mathbf{4 a}$ and $\mathbf{4 b}$, we tested the accuracy of the docking protocols used in this study by redocking VT-1161 to the active site of 5TZ1 and calculated the RMSD values of the best pose from each protocol with respect to the co-crystallized binding conformation of VT-1116. The RMSD values were 0.61, $0.64,0.77$, and $0.51 \AA$ for SP, XP, induced fit, and QPLD, respectively, showing good predictive capacity for Glide, especially with QPLD protocol, since lower RMSD means closer alignment of the two conformers (Figure 4D). Docking scores of these poses were -9.4, -6.9, -10.2, and $-7.3 \mathrm{kcal} / \mathrm{mol}$, respectively.

In general, molecular docking of $\mathbf{4 a}$ and $\mathbf{4 b}$ yielded roughly similar docking scores regarding VT-1161 (Table 3). Improvement in the scores of 4 a going from SP to QPLD was noteworthy. However, docking scores might be misleading unless associated with fulfilment of key molecular determinants. The binding modes predicted by Glide were in accordance with the general orientation of azoles in the crystallographic studies of CYP51. In the case of $\mathbf{4 a}$, improvement in the binding interactions was parallel to the improvement in the scores (Figure 5A-D). In the SP mode for 4a, Glide predicted a $\mathrm{H}$ bond with His377 via indole, with the heme $\pi$-cation via 4-chlorophenyl and $\pi$ - $\pi$ interactions via imidazole (Figure $5 \mathrm{E}$ ). In the XP mode, the $\mathrm{H}$ bond with His377 disappeared but with Induced Fit, a $\mathrm{H}$ bond with the water that mediates with Tyr132 was formed through indole NH, along with a $\pi-\pi$ stack with Phe380 through indole (Figure 5F and 5G). However, only with QPLD protocol was Glide able to model the metal coordination with the heme iron (Figure $5 \mathrm{H}$ ). In the case of $\mathbf{4 b}$, interactions with the key residues such as heme, Tyr132, and His377 were obtained, however no coordination with the iron was predicted by QPLD (See Supporting Information for details). The $\mathrm{N}^{3}$-iron distance and imidazole-protoporphyrin planar angle were especially helpful to better understand the difference between the binding modes of $\mathbf{4 a}$ and $\mathbf{4 b}$ (Table 4 ), which probably played a role in the difference of their activity results. Although these two metrics for $4 \mathbf{a}$ improved going from SP to QPLD and reached to almost ideal with QPLD (Figure 6A-D), the same was not true for $\mathbf{4 b}$ (Figure $6 \mathrm{E}-\mathrm{H}$ ). $4 \mathbf{b}^{\prime}$ 's favorable score for the pose predicted by Induced Fit was not reliable when the distance and angle metrics were considered (Figure 6G). These results clearly show that ideal interpretation of docking results is possible when docking scores and binding interactions are considered together and $\mathrm{QM} / \mathrm{MM}$ approach is more reliable and accurate than MM methods, especially when metal interactions are handled. As for $\mathbf{4 a}$, indole provided a very promising moiety for engaging with the active site gore regarding its $\mathrm{H}$ donor $\mathrm{NH}$ group, which seems to have replaced the hydroxyl of VT-1161.

Table 3. Docking scores $(\mathrm{kcal} / \mathrm{mol})$ of $\mathbf{4 a}$ and $\mathbf{4 b}$.

\begin{tabular}{ccccc}
\hline Compound & SP & XP & Induced fit & QPLD \\
\hline $\mathbf{4 a}$ & -6.5 & -6.7 & -7.9 & -8.8 \\
$\mathbf{4 b}$ & -7.3 & -4.3 & -10 & -6.0 \\
\hline
\end{tabular}

Table 4. Imidazole $\mathrm{N}^{3}$-heme iron distance $(\AA)$ and imidazole-protoporphyrin angle $\left(^{\circ}\right)$ values for the poses of $4 \mathbf{a}$ and $\mathbf{4 b}$ predicted by Glide.

\begin{tabular}{cccccc}
\hline Compound & Metric & SP & XP & Induced fit & QPLD \\
\hline \multirow{4}{4a}{} & Distance & 3.50 & 3.33 & 2.56 & 2.45 \\
& Angle & 70.6 & 68.7 & 76.8 & 79.7 \\
\multirow{4}{*}{$4 \mathbf{b}$} & Distance & 2.97 & 3.27 & 4.05 & 2.92 \\
& Angle & 48.8 & 81.3 & 63.8 & 89.1 \\
\hline
\end{tabular}




\section{CONCLUSION}

In search of potent antifungal compounds, we synthesized and tested two indole-derivative azole compounds with reference to our previous study showing the potential of indole as a tail substitution. As a result, we obtained 4a, a highly active azole compound against both susceptible and resistant Candida spp., as well as $C$. albicans biofilms. The compound was several times more potent than the reference drug, fluconazole. Docking studies with CACYP51 structure, the major target for azole antifungals, also confirmed the importance of indole, as well as the importance of $\mathrm{QM} / \mathrm{MM}$ approach in docking studies. Furthermore, the study demonstrated that 4-chlorophenyl as the aryl pharmacophore was much better than 2-naphthyl. Thus, new indole derivatives will be designed and tested as future studies to make use of this fragment for antifungal efficacy.

A

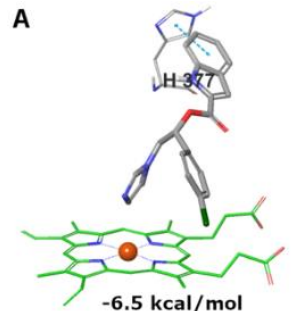

$E$

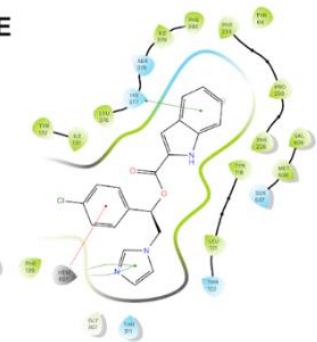

B
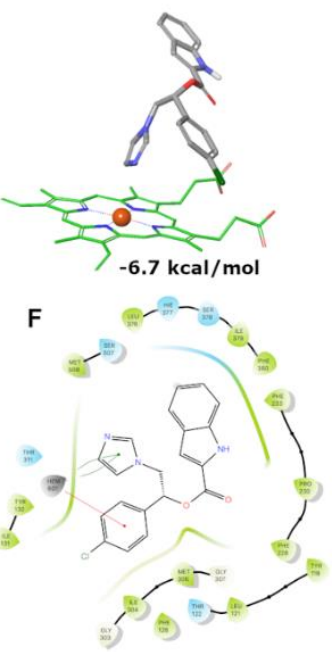

C

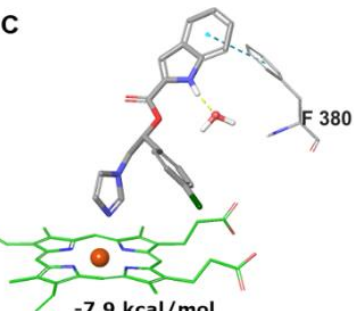

G

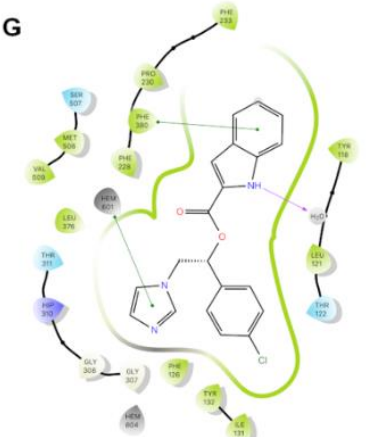

D

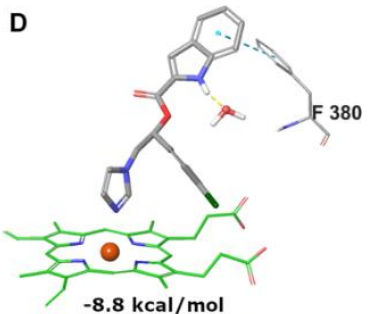

$\mathrm{H}$

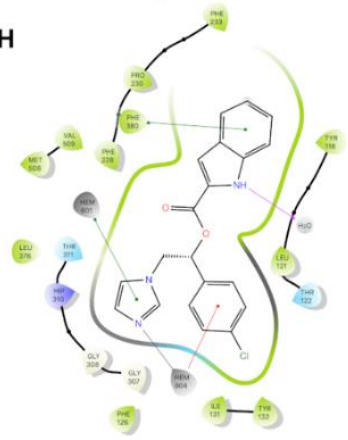

Figure 5. Binding modes (A-D) and interactions (E-H) of 4a in 5TZ1 active site predicted by SP, XP, Induced Fit, and QPLD protocols, respectively.
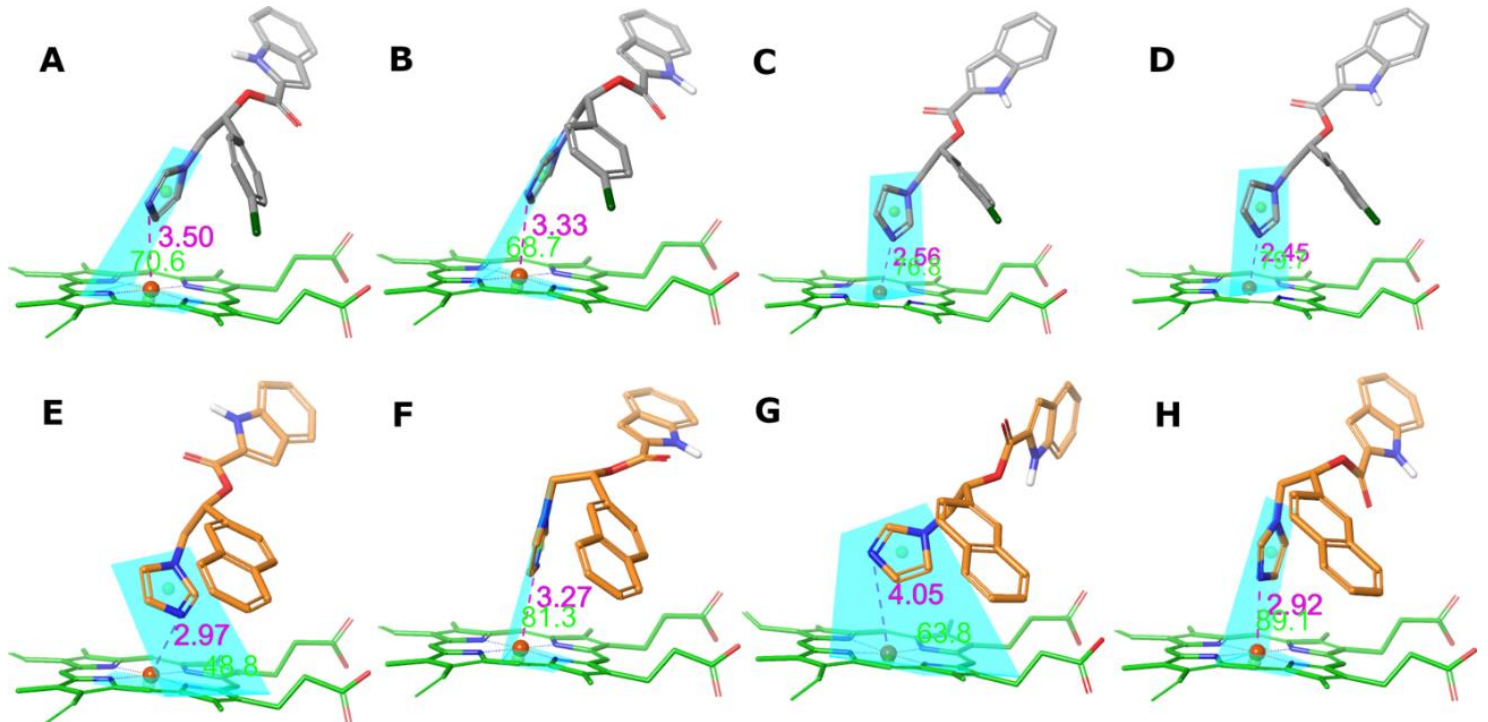

Figure 6. Coordination distances of imidazole $\mathrm{N}^{3}$ and heme iron and plane angles between imidazole and the protoporphyrin rings for the poses of $4 a(A-D)$ and $4 \mathbf{b}(\mathrm{E}-\mathrm{H})$ predicted by SP, XP, Induced Fit, and QPLD protocols, respectively. 


\section{MATERIALS AND METHODS}

\subsection{Chemistry}

All the reagents and chemicals used in this study were purchased from Sigma-Aldrich (USA) and Merck (Germany). For thin layer chromatography (TLC) Merck Kieselgel 60 F254 was used as stationary phase with chloroform-methanol (90:10) solvent system. TLC plates were inspected under $254 \mathrm{~nm}$ UV light. Melting points $(\mathrm{mp})$ were determined using a Thomas-Hoover capillary melting point apparatus (USA) and uncorrected. ${ }^{1} \mathrm{H}$ NMR $(400 \mathrm{MHz})$ and ${ }^{13} \mathrm{C}$ NMR $(125 \mathrm{MHz})$ spectra were recorded by a Varian Mercury $400 \mathrm{FT}$ (USA) and Bruker Avance 500 (Germany) NMR spectrometers, respectively. Tetramethylsilane was used as internal reference and the chemical shifts are expressed as $\delta(\mathrm{ppm})$ values. The splitting patterns are described as $\mathrm{s}$ (singlet), $\mathrm{d}$ (doublet), $\mathrm{t}$ (triplet), and $\mathrm{m}$ (multiplet). LC-MS spectra were obtained using a Micromass ZQ mass spectrometer (USA) connected to Waters Alliance HPLC (USA) with electrospray ionization (ESI+) method and MassLynx 4.1 software.

\subsubsection{Synthesis of the compounds}

The starting compounds, which were previously reported, were synthesized according to the literature methods. 2,4'-Dichloroacetophenone (1a) was purchased and 2-bromo-1-(2-naphthyl)ethanone $\mathbf{1 b}$ was afforded by bromination of commercially obtained 2-acetonaphthone (1) at the second position, and both of were reduced using $\mathrm{NaBH}_{4}$ to give 1-(4-chlorophenyl)-2-(1H-imidazol-1-yl)ethanol (3a) and 2-(1H-imidazol1-yl)-1-(2-naphthyl)ethanol (3b), respectively (See Supporting Information for details) [15-17].

The title compounds were synthesized according to Steglich esterification [18]. A mixture of indole-2carboxylic acid (1 mmol), N,N'-dicyclohexylcarbodiimide (DCC) $(1 \mathrm{mmol})$, and 4-dimethylaminopyridine (DMAP) $(0.07 \mathrm{mmol})$ in dichloromethane (DCM) was added to a mixture of $\mathbf{3 a}$ or $\mathbf{3 b}(1 \mathrm{mmol})$ in DCM at $0-5$ ${ }^{\circ} \mathrm{C}$ dropwise. The mixture was stirred for 20 minutes in ice bath $\left(0-5^{\circ} \mathrm{C}\right)$ then for 6 hours at room temperature. The precipitate was filtered off, the filtrate was kept at $-8{ }^{\circ} \mathrm{C}$ overnight, re-filtered, and evaporated under vacuum. The residue was purified via column chromatography (chloroform-methanol 90:10). 4b was converted to its $\mathrm{HCl}$ salt form using ethereal solution of gaseous $\mathrm{HCl}(\mathrm{gHCl})$. The title compounds were crystallized from methanol. Their structure and purity were validated through ${ }^{1} \mathrm{H} N M R,{ }^{13} \mathrm{C} N M R$, and LCMS spectral data.

1-(4-Chlorophenyl)-2-(1H-imidazol-1-yl)ethanol 1H-indole-2-carboxylate (4a): White powder $(150.0 \mathrm{mg}, 41 \%$ yield); mp: $182-3^{\circ} \mathrm{C}$ (methanol); ${ }^{1} \mathrm{H}$ NMR $\left(400 \mathrm{MHz}, \mathrm{DMSO}-\mathrm{d}_{6}\right): \delta=4.51\left(\mathrm{~d}, J=6.5 \mathrm{~Hz}, 2 \mathrm{H}, \mathrm{CH}_{2}\right), 6.22\left(\mathrm{t}, J_{1}=J_{2}\right.$ $=6.0 \mathrm{~Hz}, 1 \mathrm{H}, \mathrm{CHO}), 6.84-7.72\left(\mathrm{~m}, 12 \mathrm{H}, 4\right.$-chlorobenzene, indole $\mathrm{H}^{2-7}$, imidazole), $11.93\left(\mathrm{~s}, 1 \mathrm{H}\right.$, indole $\left.\mathrm{H}^{1}\right) ;{ }^{13} \mathrm{C}$ NMR (125 MHz, DMSO-d 6$)$ : $\delta=51.0\left(\mathrm{CH}_{2}\right), 74.5(\mathrm{CHO}), 109.2-138.4(17 \mathrm{C}$, aromatic), $160.4(\mathrm{CO}) ; \mathrm{LC}-\mathrm{ESI}+\mathrm{m} / \mathrm{z}$ : $369[(\mathrm{M}+3)+\mathrm{H}]+, 366(\% 100)[(\mathrm{M}+1)+\mathrm{H}]+, 298$.

2-(1H-imidazol-1-yl)-1-(2-naphthyl)ethanol 1H-indole-2-carboxylate hydrochloride (4b): White powder (191.9 $\mathrm{mg}, 46 \%$ yield); mp: $168-70{ }^{\circ} \mathrm{C}$ (methanol); ${ }^{1} \mathrm{H}$ NMR (400 MHz, DMSO- $\left.\mathrm{d}_{6}\right): \delta=4.89-4.99\left(\mathrm{~m}, 2 \mathrm{H}, \mathrm{CH}_{2}\right), 6.52-6.55$ $(\mathrm{m}, 1 \mathrm{H}, \mathrm{CHO}), 7.10-8.06\left(\mathrm{~m}, 14 \mathrm{H}\right.$, naphthalene, indole $\mathrm{H}^{3-7}$, imidazole $\left.\mathrm{H}^{4,5}\right), 9.42\left(\mathrm{~s}, 1 \mathrm{H}\right.$, imidazole $\left.\mathrm{H}^{2}\right), 12.18(\mathrm{~s}$, $1 \mathrm{H}$, indole $\left.\mathrm{H}^{1}\right) ;{ }^{13} \mathrm{C}$ NMR $\left(125 \mathrm{MHz}, \mathrm{DMSO}_{6}\right): \delta=52.9\left(\mathrm{CH}_{2}\right), 74.5(\mathrm{CHO}), 109.5-138.2(21 \mathrm{C}$, aromatic), 160.4 (CO); LC-ESI+ m/z: $383(\% 100)[(\mathrm{M}+1)+\mathrm{H}]^{+}, 314$.

\subsection{Pharmacology}

\subsubsection{Microdilution test}

The MIC values ( $\mu \mathrm{g} / \mathrm{ml})$ of $\mathbf{4 a}$ and $\mathbf{4 b}$ against the ATCC strains of C. albicans (ATCC 90028), C. krusei (ATCC 6258), and C. parapsilosis (ATCC 90018), and a clinical isolate of fluconazole-resistant C. tropicalis were determined by broth microdilution method according to the Clinical and Laboratory Standards Institute (CLSI) reference document (M27-A3) [37]. Fluconazole was used as positive control. First, the fungi, which were stored at $-80^{\circ} \mathrm{C}$ in glycerol, were thawed and subcultured twice onto Sabouraud dextrose agar. RPMI 1640 broth (ICN-Flow, Aurora, OH, USA, with glutamine, without bicarbonate and with $\mathrm{pH}$ indicator) buffered to $\mathrm{pH} 7.0$ with 3-N-morpholinopropanesulfonic acid (Sigma, USA) was used and the inoculum densities were prepared out of 24-hour subcultures. The final test concentration of the fungi was 0.5 to $2.5 \times$ $10^{3} \mathrm{cfu} / \mathrm{ml}$. Fluconazole was dissolved in sterile deionized distilled water at $64-0.0625 \mu \mathrm{g} / \mathrm{ml}$. The test compounds were dissolved in dimethyl sulfoxide (Sigma, USA) and diluted using distilled water so that the final twofold concentrations of the compounds prepared in microtiter plate wells were in the range of 1024- 
$0.25 \mu \mathrm{g} / \mathrm{ml}$. The plates were incubated at $35^{\circ} \mathrm{C}$ for 48 hours and the MIC values were determined as the lowest concentration in which fungal growth was not visible.

\subsubsection{Biofilm test}

Antibiofilm activities of $\mathbf{4 a}$ and $\mathbf{4 b}$ were evaluated by determination of their minimum biofilm inhibitory and eradication concentrations (MBIC and MBEC) against C. albicans ATCC MYA-2876 biofilms according to the MBEC ${ }^{\mathrm{TM}}$ assay protocol supplied by the manufacturer (Innovotech Inc., Canada) using amphotericin B as positive control. In this standard ASTM method, the biofilms were grown in the Calgary Biofilm Device (MBEC Assay ${ }^{\mathrm{TM}}$ for Physiology \& Genetics, P\&G, Innovotech Inc., Canada). Aliquots of $150 \mu \mathrm{l}$ final inoculum suspensions $\left(10^{6} \mathrm{cfu} / \mathrm{ml}\right)$ were transferred to each test well and the MBEC assay plate lids with 96 pegs were placed into the microtiter plates, which were incubated for 48 hours at $37^{\circ} \mathrm{C}$ to form mature biofilms. Then, the peg lids were rinsed three times with $100 \mu 10.9 \%$ saline and transferred to a challenge plate. Finally, 200 $\mu \mathrm{l}$ serial twofold dilutions of each compound were added to each well and the plates were incubated for 24 hours at $35{ }^{\circ} \mathrm{C}$. The test compounds were at the concentration range of $512-0.5 \mu \mathrm{g} / \mathrm{ml}$ in columns $1-11$, respectively. Positive growth control and sterility control were also included in each assay plate. Following the incubation, the peg lids were rinsed three times with $0.9 \%$ saline and transferred to a recovery plate with each well containing RPMI 1640 supplemented with $2 \%$ glucose. The plates were sonicated for five minutes to pass the biofilms into the recovery media and the peg lids were discarded. The recovery plates were incubated overnight and the optical density of each well was measured at $550 \mathrm{~nm}$ by spectrophotometer. The plates were also visually checked after 24 hours for turbidity and the clear wells were kept as evidence for biofilm eradication. The MBEC values were determined by identifying the lowest compound concentration that prevented regrowth of $C$. albicans from the treated biofilms and the MBIC values by identifying the minimum concentration that prevented the initial formation of biofilms by visual inspection of the wells for turbidity.

\subsection{Molecular modeling}

\subsubsection{Preparation of the ligands and the receptor}

Compound 4a and $\mathbf{4 b}$ were modelled and prepared using LigPrep (2019-4, Schrödinger, LLC, New

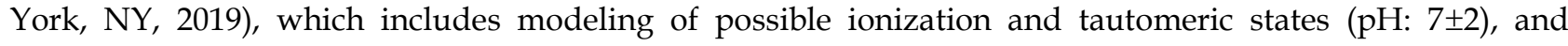
enantiomers. Geometric optimization was performed using MacroModel (2019-4, Schrödinger, LLC, New York, NY, 2019) and conjugate gradients method according to OPLS3e forcefield parameters [38]. Molecular descriptors were calculated for the compounds with QikProp.

5TZ1 (resolution: $2.00 \AA$ ) was downloaded from RCSB Protein Data Bank (www.rcsb.org) [39] and prepared using the Protein Preparation Wizard (Epik, Impact, Prime: 2019-4, Schrödinger, LLC, New York, NY, 2019) of Maestro (2019-4, Schrödinger, LLC, New York, NY, 2019) [40]. In this process, chain B and waters beyond $3 \AA$ from the ligand were removed, missing sidechain atoms and hydrogen atoms were added, bond orders, partial charges, ionization and tautomeric states, and $\mathrm{H}$ bonds were assigned.

\subsubsection{Molecular docking protocol}

Using receptor grid generation panel of Maestro, the active site grid was prepared taking the central coordinates of VT-1161 $(70.66,66.25,4.35)$ and setting each dimension of the grid box as $20 \AA$. The ligands were docked flexibly to the receptor using the generated grid files by Glide at SP and XP modes, as well as using Induced Fit and QPLD protocols. At SP and XP modes, docking was performed at 50 runs per ligand, Epik state penalties were added to the scores, and post-docking minimization was enabled. In the Induced Fit docking protocol, each ligand was initially docked to the same coordinates 20 times with ligand and receptor van der Waals radii scaled to 0.5 . Then the residues within $5.0 \AA$ to each ligand pose were optimized using Prime and the ligands were redocked to the refined receptor structures within $30 \mathrm{kcal} / \mathrm{mol}$ to the best structure and within the best 20 structures at XP mode with 20 runs per ligand. In the QPLD protocol, the prepared grid files were used directly for the initial docking at XP mode with a maximum of 10 poses. Single-point energy calculation was performed using QSite (2019-4, Schrödinger, LLC, New York, NY, 2019) [41] with ab initio charges of ligands being calculated by Jaguar (2019-4, Schrödinger, LLC, New York, NY, 2019) at fast level [42]. Then each pose was redocked at XP mode with the same settings and final 10 poses were selected for each ligand according to Glide GScore. Each docking pose from all protocols were visually evaluated for the molecular determinants of CYP51 inhibition. 
Acknowledgements: We are thankful to Prof. Erhan Palaska for providing the LC-MS data.

Author contributions: Concept - S.S., D.K.; Design - S.S.; Supervision - S.S.; Resources - S.S., D.K.; Materials - S.S. D.K.; Data Collection and/or Processing - S.S., D.K.; Analysis and/or Interpretation - S.S., D.K.; Literature Search S.S.; Writing - S.S., D.K.; Critical Reviews - S.S., D.K.

Conflict of interest statement: The authors declared no conflict of interest.

\section{Appendix A. Supplementary Material}

Supplementary material related to this article can be accessed at http://doi.org/10.35333/jrp.2020.223.

\section{REFERENCES}

[1] Wong SSW, Samaranayake LP, Seneviratne CJ. In pursuit of the ideal antifungal agent for Candida infections: highthroughput screening of small molecules. Drug Discov Today. 2014; 19(11): 1721-1730. [CrossRef]

[2] Graybill JR. Future directions of antifungal chemotherapy. Clin Infect Dis. 1992; 14(Suppl 1): S170-181. [CrossRef]

[3] Silva S, Rodrigues CF, Araujo D, Rodrigues ME, Henriques M. Candida Species Biofilms' Antifungal Resistance. J Fungi. 2017; 3(1): 8. [CrossRef]

[4] Maertens JA. History of the development of azole derivatives. Clin Microbiol Infect. 2004; 10(Suppl 1): 1-10. [CrossRef]

[5] Zhang J, Li L, Lv Q, Yan L, Wang Y, Jiang Y. The Fungal CYP51s: Their Functions, Structures, Related Drug Resistance, and Inhibitors. Front Microbiol. 2019; 10: 691. [CrossRef]

[6] Correia MA, Ortiz de Montellano PR. Inhibition of Cytochrome P450 Enzymes. In: Ortiz de Montellano PR. (Ed). Cytochrome P450: Structure, Mechanism, and Biochemistry. Springer US, Boston, 2005, pp. 247-322.

[7] Madhosingh H, Southwick FS. Infectious Diseases. In: Harward MP. (Ed). Medical Secrets. Mosby, Saint Louis, 2012, pp. 344-375.

[8] Hargrove TY, Friggeri L, Wawrzak Z, Qi A, Hoekstra WJ, Schotzinger RJ, York JD, Guengerich FP, Lepesheva GI. Structural analyses of Candida albicans sterol 14alpha-demethylase complexed with azole drugs address the molecular basis of azole-mediated inhibition of fungal sterol biosynthesis. J Biol Chem. 2017; 292(16): 6728-6743. [CrossRef]

[9] Hoekstra WJ, Hargrove TY, Wawrzak Z, da Gama Jaen Batista D, da Silva CF, Nefertiti AS, Rachakonda G, Schotzinger RJ, Villalta F, Soeiro Mde N, Lepesheva GI. Clinical Candidate VT-1161's Antiparasitic Effect In Vitro, Activity in a Murine Model of Chagas Disease, and Structural Characterization in Complex with the Target Enzyme CYP51 from Trypanosoma cruzi. Antimicrob Agents Chemother. 2016; 60(2): 1058-1066. [CrossRef]

[10] Monk BC, Tomasiak TM, Keniya MV, Huschmann FU, Tyndall JD, O'Connell JD, Cannon RD, McDonald JG, Rodriguez A, Finer-Moore JS, Stroud RM. Architecture of a single membrane spanning cytochrome P450 suggests constraints that orient the catalytic domain relative to a bilayer. Proc Natl Acad Sci U S A. 2014; 111(10): 3865-3870. [CrossRef]

[11] Sagatova AA, Keniya MV, Wilson RK, Sabherwal M, Tyndall JD, Monk BC. Triazole resistance mediated by mutations of a conserved active site tyrosine in fungal lanosterol 14alpha-demethylase. Sci Rep. 2016; 6: 26213. [CrossRef]

[12] Dogan IS, Sarac S, Sari S, Kart D, Gokhan SE, Vural I, Dalkara S. New azole derivatives showing antimicrobial effects and their mechanism of antifungal activity by molecular modeling studies. Eur J Med Chem. 2017; 130: 124-138. [CrossRef]

[13] Sari S, Kart D, Sabuncuoglu S, Dogan IS, Ozdemir Z, Bozbey I, Gencel M, Essiz S, Reynisson J, Karakurt A, Sarac S, Dalkara S. Antifungal screening and in silico mechanistic studies of an in-house azole library. Chem Biol Drug Des. 2019; 94(5): 1944-1955. [CrossRef]

[14] Sari S, Kart D, Ozturk N, Kaynak FB, Gencel M, Taskor G, Karakurt A, Sarac S, Essiz S, Dalkara S. Discovery of new azoles with potent activity against Candida spp. and Candida albicans biofilms through virtual screening. Eur J Med Chem. 2019; 179: 634-648. [CrossRef]

[15] Baji H, Flammang M, Kimny T, Gasquez F, Compagnon PL, Delcourt A. Synthesis and antifungal activity of novel (1-aryl-2-heterocyclyl)ethylideneaminooxymethyl-substituted dioxolanes. Eur J Med Chem. 1995; 30(7): 617-626. [CrossRef] 
[16] Godefroi EF, Heeres J, Van Cutsem J, Janssen PA. The preparation and antimycotic properties of derivatives of $1-$ phenethylimidazole. J Med Chem. 1969; 12(5): 784-791. [CrossRef]

[17] Immediata T, Day AR. $\beta$-Naphthyl derivatives of ethanolamine and n-substituted ethanolamines. J Org Chem. 1940; 05(5): 512-527. [CrossRef]

[18] Neises B, Steglich W. Simple Method for the Esterification of Carboxylic Acids. Angew Chem Int Ed. 1978; 17(7): 522524. [CrossRef]

[19] Cavalheiro M, Teixeira MC. Candida Biofilms: Threats, Challenges, and Promising Strategies. Front Med. 2018 ; 5: 28. [CrossRef]

[20] Kuhn DM, George T, Chandra J, Mukherjee PK, Ghannoum MA. Antifungal susceptibility of Candida biofilms: unique efficacy of amphotericin B lipid formulations and echinocandins. Antimicrob Agents Chemother. 2002; 46(6): 1773-1780. [CrossRef]

[21] Melo AS, Bizerra FC, Freymuller E, Arthington-Skaggs BA, Colombo AL. Biofilm production and evaluation of antifungal susceptibility amongst clinical Candida spp. isolates, including strains of the Candida parapsilosis complex. Med Mycol. 2011; 49(3): 253-262. [CrossRef]

[22] Wang J. Comprehensive assessment of ADMET risks in drug discovery. Curr Pharm Des. 2009; 15(19): $2195-2219$. [CrossRef]

[23] Lipinski CA, Lombardo F, Dominy BW, Feeney PJ. Experimental and computational approaches to estimate solubility and permeability in drug discovery and development settings. Adv Drug Deliv Rev. 2001; 46(1-3): 3-26. [CrossRef]

[24] Veber DF, Johnson SR, Cheng HY, Smith BR, Ward KW, Kopple KD. Molecular properties that influence the oral bioavailability of drug candidates. J Med Chem. 2002; 45(12): 2615-2623. [CrossRef]

[25] Zhu F, Logan G, Reynisson J. Wine Compounds as a Source for HTS Screening Collections. A Feasibility Study. Mol Inform. 2012; 31(11-12): 847-855. [CrossRef]

[26] Baell J, Walters MA. Chemistry: Chemical con artists foil drug discovery. Nature. 2014; 513(7519): 481-483. [CrossRef]

[27] Schell WA, Jones AM, Garvey EP, Hoekstra WJ, Schotzinger RJ, Alexander BD. Fungal CYP51 Inhibitors VT-1161 and VT-1129 Exhibit Strong In Vitro Activity against Candida glabrata and C. krusei Isolates Clinically Resistant to Azole and Echinocandin Antifungal Compounds. Antimicrob Agents Chemother. 2017; 61(3): e01817-16. [CrossRef]

[28] Chau AS, Mendrick CA, Sabatelli FJ, Loebenberg D, McNicholas PM. Application of real-time quantitative PCR to molecular analysis of Candida albicans strains exhibiting reduced susceptibility to azoles. Antimicrob Agents Chemother. 2004; 48(6): 2124-2131. [CrossRef]

[29] Rupp B, Raub S, Marian C, Holtje HD. Molecular design of two sterol 14alpha-demethylase homology models and their interactions with the azole antifungals ketoconazole and bifonazole. J Comput Aided Mol Des. 2005; 19(3): 149163. [CrossRef]

[30] Zheng H, Langner KM, Shields GP, Hou J, Kowiel M, Allen FH, Murshudov G, Minor W. Data mining of iron(II) and iron(III) bond-valence parameters, and their relevance for macromolecular crystallography. Acta Crystallogr D Struct Biol. 2017; 73(Pt 4): 316-325. [CrossRef]

[31] Keniya MV, Sabherwal M, Wilson RK, Woods MA, Sagatova AA, Tyndall JDA, Monk BC. Crystal Structures of FullLength Lanosterol 14alpha-Demethylases of Prominent Fungal Pathogens Candida albicans and Candida glabrata Provide Tools for Antifungal Discovery. Antimicrob Agents Chemother. 2018; 62(11): e01134-18. [CrossRef]

[32] Friesner RA, Banks JL, Murphy RB, Halgren TA, Klicic JJ, Mainz DT, Repasky MP, Knoll EH, Shelley M, Perry JK, Shaw DE, Francis P, Shenkin PS. Glide: a new approach for rapid, accurate docking and scoring. 1 . Method and assessment of docking accuracy. J Med Chem. 2004; 47(7): 1739-1749. [CrossRef]

[33] Friesner RA, Murphy RB, Repasky MP, Frye LL, Greenwood JR, Halgren TA, Sanschagrin PC, Mainz DT. Extra precision glide: docking and scoring incorporating a model of hydrophobic enclosure for protein-ligand complexes. J Med Chem. 2006; 49(21): 6177-6196. [CrossRef]

[34] Halgren TA, Murphy RB, Friesner RA, Beard HS, Frye LL, Pollard WT, Banks JL. Glide: a new approach for rapid, accurate docking and scoring. 2. Enrichment factors in database screening. J Med Chem. 2004; 47(7): 1750-1759. [CrossRef]

[35] Sherman W, Day T, Jacobson MP, Friesner RA, Farid R. Novel procedure for modeling ligand/receptor induced fit effects. J Med Chem. 2006; 49(2): 534-553. [CrossRef] 
[36] Cho AE, Guallar V, Berne BJ, Friesner R. Importance of accurate charges in molecular docking: quantum mechanical/molecular mechanical (QM/MM) approach. J Comput Chem. 2005; 26(9): 915-931. [CrossRef]

[37] Clinical and Laboratory Standards Institute (CLSI), Reference Method for Broth Dilution Antifungal Susceptibility Testing of Yeasts; Approved Standard, third ed. CLSI document M27-A3. Clinical and Laboratory Standards Institute, PA, USA 2008

[38] Harder E, Damm W, Maple J, Wu C, Reboul M, Xiang JY, Wang L, Lupyan D, Dahlgren MK, Knight JL, Kaus JW, Cerutti DS, Krilov G, Jorgensen WL, Abel R, Friesner RA. OPLS3: A Force Field Providing Broad Coverage of Druglike Small Molecules and Proteins. J Chem Theory Comput. 2016; 12(1): 281-296. [CrossRef]

[39] Berman HM, Westbrook J, Feng Z, Gilliland G, Bhat TN, Weissig H, Shindyalov IN, Bourne PE. The Protein Data Bank. Nucleic Acids Res. 2000; 28(1): 235-242. [CrossRef]

[40] Sastry GM, Adzhigirey M, Day T, Annabhimoju R, Sherman W. Protein and ligand preparation: parameters, protocols, and influence on virtual screening enrichments. J Comput Aided Mol Des. 2013; 27(3): 221-234. [CrossRef]

[41] Murphy RB, Philipp DM, Friesner RA. A mixed quantum mechanics/molecular mechanics (QM/MM) method for large-scale modeling of chemistry in protein environments. J Comput Chem. 2000; 21(16): 1442-1457. [CrossRef]

[42] Bochevarov AD, Harder E, Hughes TF, Greenwood JR, Braden DA, Philipp DM, Rinaldo D, Halls MD, Zhang J, Friesner RA. Jaguar: A high-performance quantum chemistry software program with strengths in life and materials sciences. Int J Quantum Chem. 2013; 113(18): 2110-2142. [CrossRef]

This is an open access article which is publicly available on our journal's website under Institutional Repository at http://dspace.marmara.edu.tr. 